\title{
Incidence of hereditary thrombofilies in a population of Mexican women
}

\author{
Abstract \\ Objective: To report the incidence of thrombophilias and importance in the development of \\ thrombotic events in a population of Mexican women.
}

Methods: Is a retrospective, observational and cross-sectional study of 184 women of reproductive age, where the age, weight, height and study of hereditary thrombophilias of FVL-G1691A, PT-G20210A, MTHFR-C677T and PAI-1 4G/5G were studied. Four groups were formed: 1) FVL-G1691A, 2) PT-G20210A, 3) MTHFR-C677T and 4) PAI-1 4G/5G, each group was separated by homozygous and heterozygous mutation.

Results: MTHFR-C677T and PAI-1 4G/5G present higher incidence (48.9 and 64\%), when comparing with FVL-G1691A and PT-G20210A (3.8 and 0.5\%) $(\mathrm{p}<0.05)$, higher incidence of PAI-1 4G/5G was observed, when compared to MTHFR-C677T (64.6 vs. $48.9 \%, \mathrm{p}<0.05)$, difference that was not observed when comparing FVL-G1691A with PTG20210A (3.8 vs. $0.5 \%, p>0.05$ ). When patients presented only one thrombophilia, the highest incidence is of MTHFR-C677T and PAI-1 4G $>5 \mathrm{G}$ (16.5 and 35.2\%). Patients with multiple thrombophilias had an incidence of MTHFR-C677T with PAI-1 4G/5G of $30.2 \%$.

Conclusion: Our results in the population of Mexican women, we report a high incidence of the MTHFR-C677T and PAI-1 4G / 5G mutation, which makes them susceptible to the development of thrombotic events.

Keywords: thrombophilia, miscarriage, thrombosis, coagulation, deep vein thrombosis, mutation
Volume II Issue 4 - 2020

\author{
Lujan Irastorza Jesús Estuardo,' Durand \\ Montaño Carlos,' Ávila Pérez Felipe de \\ Jesús,' Ávila Rebollar Daniela,' Pariente \\ Fernández Maruxa,' Vargas Hernández Víctor \\ Manuel $^{2}$ \\ 'Clínica de Ginecología y obstétrica (PRONATAL), Mexico \\ ${ }^{2}$ Clínica de Salud Femenina, Mexico
}

Correspondence: Vargas Hernández Víctor Manuel, Clínica de Salud Femenina, Mexico, Tel (52) 5552I79782, Fax (52)5555746647, Email vvargashernandez@yahoo.com.mx

Received: May 2I, 2020 | Published: July 16, 2020

\section{Background}

Thrombophilia is defined as an abnormal tendency to form venous thrombosis that can result in deep vein thrombosis. ${ }^{1}$

The clinical pattern of deep vein thrombosis shows wide heterogeneity, although they have the same thrombophilia defect. Common risk factors associated with deep vein thrombosis are obesity, smoking, blood group (ABO), and polymorphisms. The distinct thrombophilias causes different severities in the tendency to thrombosis and not all can be treated in the same way. Furthermore, more than one predisposing condition exists in the same individual, example of this are other defects such as protein S deficiency, caused by more than one genetic mutation. These different mutations differ in their phenotypic presentations, and other factors. ${ }^{2}$

Thrombophilias in pregnancy are related to maternal-fetal morbidity and mortality, due to the physiological changes of pregnancy, which is a state of hypercoagulability, making women more prone to hypercoagulation, and susceptible to pathological processes such as deep vein thrombosis. The incidence of maternal mortality is reported in emerging countries of 1 in 1000, with the greatest increase during the puerperium: $;{ }^{3-5}$ where, mainly, they can develop venous thrombosis or deep vein thrombosis, particularly, with a higher incidence in the lower limbs than in the arms and abdomen,$^{6}$ it is associated with circulatory and cardiac problems, alteration of reproductive functions and failure in embryo implantation. Thrombophilias can be acquired; such as antiphospholipid syndrome, hyperhomocysteinemia (nongenetic), hypothyroidism, increased activity in clotting factors such as IX, XI or VIII, deficiency of plasminogen and acquired resistance to activated protein $\mathrm{C}$ and inherited thrombophilias, such as polymorphism of a single nucleotide of factor V Leiden (FVLG1691A) and prothrombin (PT-G20210A), overexpression leads to activation of thrombin, which is a protein involved in the hemostasis system for clot formation (hypercoagulability) (Figure 1). ${ }^{7-9}$

These two thrombophilias are more common and associated with an increased risk of developing deep vein thrombosis (symptomatic or asymptomatic) and pulmonary thromboembolism. ${ }^{10}$

Exist other thrombophilias that have an impact on the formation of venous thrombosis, not only because of their participation as an activator in the coagulation cascade, but also because some of these factors inhibit coagulation and, being inactive or blocked, allow the formation of clots, ${ }^{411-14}$ is the case of the methylenetetrahydrofolate reductase mutation (MTHFR-C677T) and the plasminogen activator-1 inhibitor (PAI-1 4G/5G).

MTHFR-C677T develops an increase in homocysteine concentrations, which increases the production of thromboxanes that favor platelet aggregation and the development of venous thrombosis (Figure 2). ${ }^{15-18}$

In turn, PAI-1, is a factor that participates in fibrinolysis, its PAI$14 \mathrm{G} / 5 \mathrm{G}$ mutation increases levels of PAI-1 in plasma allowing the formation of clots and the possible generation of venous thrombosis (Figure 1). ${ }^{9,17,19,20-22}$ In addition to this, there are studies that report that the presence of FVL-G1691A, PT-G20210A, MTHFR-C677T and PAI-1 5G>4G, can generate complications during pregnancy, such as alterations in early and late embryogenesis, increased risk of preeclampsia, early loss of pregnancy, intrauterine growth restriction, premature placental abruption, fetal, neonatal death, and recurrent gestational loss. ${ }^{8,23-27}$ 
The objective of this work is to report the incidence of these four thrombophilias and their importance with respect to the development of thrombotic events in a population of Mexican women.

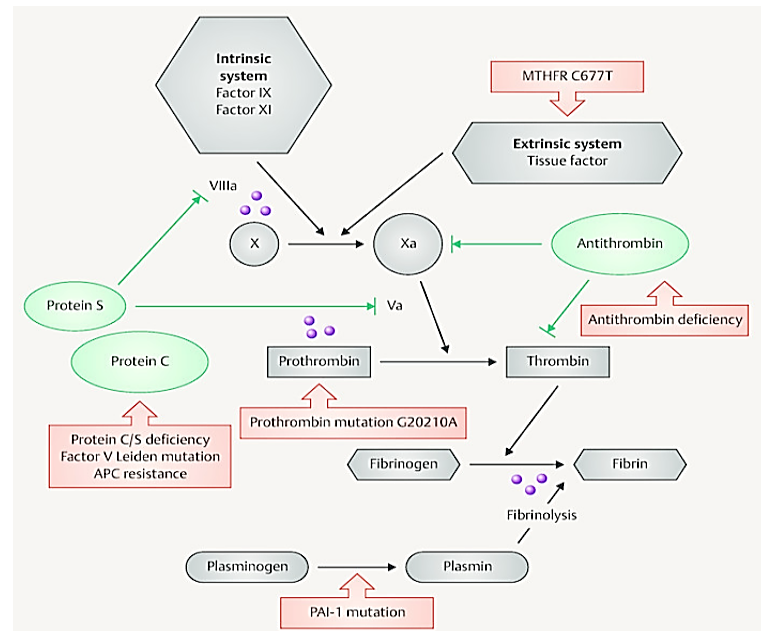

Figure I Shows the level in which FVL (Va), Prothrombin, MTHFR and PAI-I participate. Image obtained from Stefanski A, et al.,"

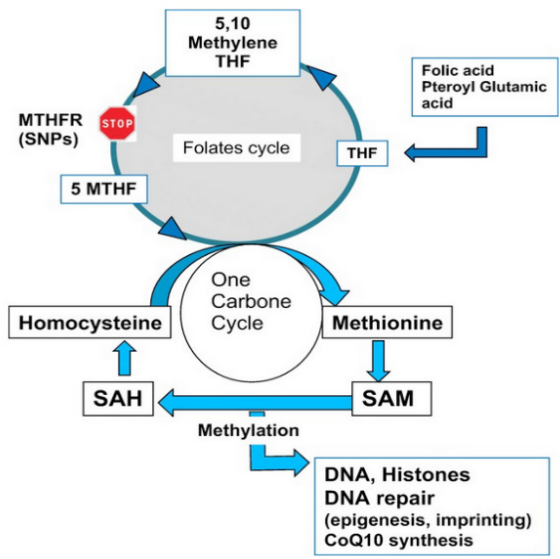

Figure 2 Shows the participation of MTHFR in the folate cycle. MTHF, 5 methyltetrahydrofolate; MTHFR SNP, methylene tetrahydrofolate reductase singlenucleotide polymorphism; SAH, S adenosyl homocysteine; SAM, S adenosyl methionine; THF, tetrahydrofolate. Image taken from Goyco $L$, et al., ${ }^{18}$ SAH (S adenosyl homocysteine) and SAM (S adenosyl methionine).

\section{Material and methods}

It is a retrospective, observational and cross-sectional study, where 184 Mexican women of reproductive age were included, which were attended in the gynecology and obstetrics clinic (Pronatal), during the period 2015-2018. Inclusion criteria: Women who underwent a study of hereditary thrombophilias (FVL-G1691A, PT-G20210A, MTHFRC677T and PAI -1 4G/5G), including pregnant or nonpregnant women with a history of gestational loss, preeclampsia, intrauterine growth restriction, stillbirth, placental abruption, neonatal death, family background, and uncomplicated term pregnancies. Exclusion criteria: patients with non-inherited thrombophilias.

Four groups were formed with the obtained data: 1) FVL-G1691A, 2) PT-G20210A, 3) MTHFR-C677T and 4) PAI-1 4G/5G. Additionally, each group was separated by homozygous and heterozygous mutation: FVL-G1691A (homozygous=AA and Heterozygous=GA),
PT-G20210A (Homozygous =AA and Heterozygous=GA), MTHFRC677T (Homozygous=TT and Heterozygous $=\mathrm{CT}$ ) and PAI-1 4G/5G (homozygous $=4 \mathrm{G} / 4 \mathrm{G}$ and heterozygous $=4 \mathrm{G} / 5 \mathrm{G}$ ). Age, weight and height were studied in the first consultation.

The analysis of the thrombophilias was carried out by taking a peripheral blood sample, and it was sent to the laboratory of the Institute of Human Reproduction Sciences, where it was analyzed if they presented polymorphism of a single nucleotide, polymorphism of FVL-G1691A, PT-G20210A, MTHFR-C677T and PAI-1 4G/5G, using the polymerase chain reaction technique.

All women were offered study information and asked for their letter of informed consent; on the use and management of data privacy (age, weight, height, and thrombophilic results) to be included in the study. The inclusion criteria were women of reproductive age, with a study of thrombophilias (FVL-G1691A, PT-G20210A, MTHFRC677T and PAI-1 4G/5G); complete files (age, weight, height and thrombophilias study), study of positive and negative thrombophilias. Exclusion criteria were women without study of thrombophilias or who did not accept their inclusion in the study. Age, weight and height are reported with mean \pm standard deviation. On the other hand, the difference in incidence between the different thrombophilias and the homozygous vs. heterozygous version was performed with a chi2 using the SPSS version 25 statistical package.

\section{Results}

The analysis of our results showed that the polymorphism of MTHFR-C677T and PAI-1 4G/5G, presented a higher incidence of $48.9 \%$ and $65 \%$ respectively, where the homozygous form represented 16.8\% (MTHFR-C677T) and 21.7\% (PAI-1 4G/5G) and the heterozygous form 32\% (MTHFR-C677T) and 42.9\% (PAI$14 \mathrm{G} / 5 \mathrm{G})$. The high incidence of MTHFR-C677T and PAI-1 4G/5G represents a risk, because Mexican women may have a greater predisposition to develop thrombosis; Table 1 gives information on the age, weight, height, and body mass index (BMI) of 184 women who were included in the study.

Table I Shows population size. Age, weight, height and BMI (mean \pm SD)

\begin{tabular}{lc}
\hline \multicolumn{2}{l}{ Population characteristics } \\
\hline Age (years) & $33.6 \pm 5.1$ \\
Weight $(\mathrm{Kg})$ & $60.7 \pm 10.2$ \\
Height $(\mathrm{cm})$ & $167.8 \pm 6.3$ \\
BMl $\left(\mathrm{Kg} / \mathrm{m}^{2}\right)$ & 21.5 \\
\hline
\end{tabular}

In Figure 3, it is observed that MTHFR-C677T and PAI-1 4G/5G have a higher incidence (48.9 and 64\%), when compared with FVLG1691A and PT-G20210A (3.8 and 0.5\%) $(\mathrm{p}<0.05)$. In addition, a higher incidence of PAI-1 4G/5G was observed, when compared with MTHFR-C677T (64.6 vs. $48.9 \%, p<0.05)$, difference that was not observed when comparing FVL-G1691A with PT-G20210A (3.8 vs. $0.5 \%, \mathrm{p}>0.05)$.

It is shown in Figure 4, that MTHFR-C677T ( 16.8 vs. 32, $\mathrm{p}<0.05$ ) and PAI-1 4G/5G (21.7 vs. 42.9, $\mathrm{p}<0.05)$, have a higher incidence in their Heterozygous form when compared with the Homozygous. In the case of the FVL-G1691A (1.6 vs 2.1, p>0.05) and PT-G20210A (0 vs $0.5, p>0.05$ ), they did not present a significant difference between its homozygous and heterozygous form; Figure 3, Shows incidence 
of FVL-G1691A, PT-G20210A, MTHFR-C677T and PAI-1 4G/5G* Significant difference $(\mathrm{p}<0.05)$ when comparing MTHFR-C677T versus FVL-G1691A and PT-G20210A **. Significant difference $(\mathrm{p}<0.05)$ when comparing PAI-1 G4 $>5 \mathrm{G}$ versus MTHFR-C677T, FVL-G1691A and PT-G20210A. In Figure 5, it describes when the patients presented only one thrombophilia, the highest incidence is of MTHFR-C677T and PAI-1 4G/5G (16.5 and 35.2\%), different from FVL-G1691A and PT-G20210A, which were not presented individually in no patient. An incidence of MTHFR-C677T with PAI-1 $4 \mathrm{G} / 5 \mathrm{G}$ of $30.2 \%$ was seen in patients who had multiple thrombophilias. On the other hand, FVL-G1691A and PT-G20210A were only evident in combination with MTHFR-C677T and / or PAI$14 \mathrm{G} / 5 \mathrm{G}$, without exceeding $1.5 \%$. Finally, the percentage of patients who did not present any of these four thrombophilias was $13.6 \%$. Figure 4 shows incidence of FVL-G1691A, PT-G20210A, MTHFRC677T and PAI-1 4G/5G, in its heterozygous and homozygous form* Significant difference $(\mathrm{p}<0.05)$ when comparing homozygous vs. heterozygous MTHFR-C677T **. Significant difference $(p<0.05)$ when comparing homozygous versus heterozygous PAI-1 G4/5G. Figure 5 shows the incidence of combinations of thrombophilias presented by the population.

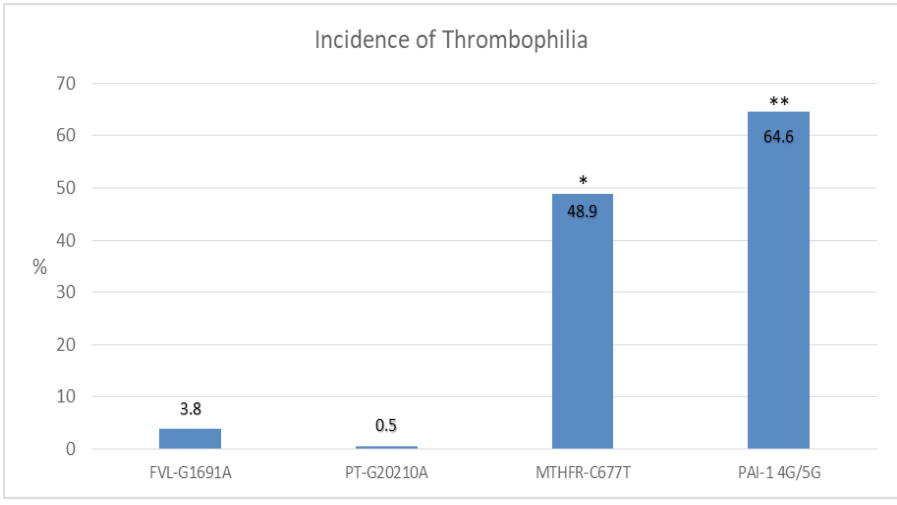

Figure 3 Shows incidence of FVL-GI69|A, PT-G202 I0A, MTHFR-C677T y PAI-I 4G/5G. *Significant difference $(p<0.05)$ when comparing with MTHFRC677T vs FVL-GI 691 IA y PT-G202 IOA. ** Significant difference $(p<0.05)$ when comparing with PAI-I G4/5G vs MTHFR-C677T, FVL-GI69|A y PT-G202IOA.

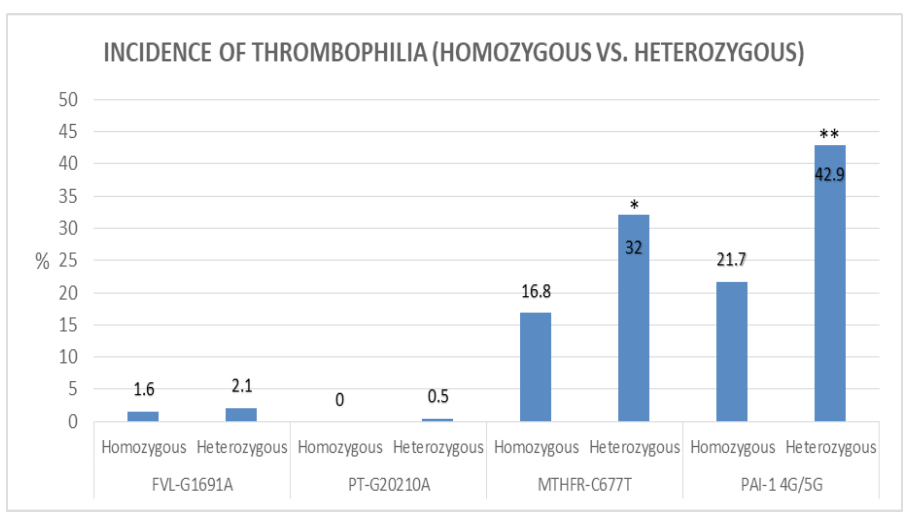

Figure 4 Shows incidence FVL-GI69IA, PT-G202I0A, MTHFR-C677T y PAII 4G/5G, in its heterozygous and homozygous form. *Significant difference $(p<0.05)$ when comparing MTHFR-C677T homozygous vs heterozygous. ** Significant difference $(p<0.05)$ when comparing PAI-I G4/5G homozygous vs heterozygous.

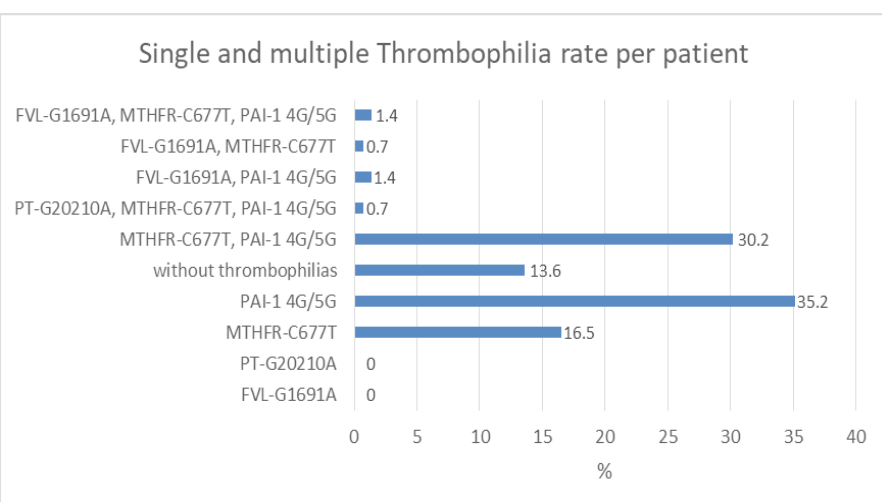

Figure $\mathbf{5}$ Shows the incidence of combination of thrombophilia presented by the population.

\section{Discussion}

Thrombophilias and their development of thrombotic events in a Mexican female population; There are many studies carried out on the incidence of thrombophilias, however, in Mexico there is still no representative sample that indicates the trend of FVL-G1691A, PT-G20210A, MTHFR-C677T and PAI-1 4G/5G, which has great importance for our environment this study.

For its part, the analysis of our results showed that the polymorphism of MTHFR-C677T and PAI-1 4G/5G, present a high incidence of $48.9 \%$ and $65 \%$ respectively, where the homozygous form represented 16.8\% (MTHFR-C677T) and 21.7\% (PAI-1 4G/5G) and the heterozygous form 32\% (MTHFR-C677T) and 42.9\% (PAI$14 \mathrm{G} / 5 \mathrm{G})$; with similar results in different regions of Europe and Asia. ${ }^{26,30-35}$

The high incidence of MTHFR-C677T and PAI-1 4G/5G represents a risk, because Mexican women may have a greater predisposition to develop venous thrombosis and deep vein thrombosis, due to the alteration of the coagulation mechanisms induced by these thrombophilias. Reports in studies where high homocysteine concentrations of up to $24 \mu \mathrm{mol} / \mathrm{L}$ and lack of fibrinolysis inhibition have been associated with the development of venous thrombosis and deep vein thrombosis. ${ }^{36-40}$ Additionally, some studies of Patients with venous thrombosis or deep vein thrombosis have reported an incidence of MTHFR-C677T of up to $35 \%$, showing that both the control group and the group with venous thrombosis or deep vein thrombosis have similar incidences. ${ }^{41-43}$

This is due to the fact that thrombosis or deep vein thrombosis have different risk factors ${ }^{44} 6$, other report on PAI-1 4G/5G, associate the development of venous thrombosis or thrombosis deep venous mainly to the homozygous form ( 25.8 versus $14.7 \%$ ), which was the only one that presented a significant difference when compared with the control group. ${ }^{45}$

In turn, FVL-G1691A and PT-G20210A, presented an incidence of $3.8 \%$ and $0.5 \%$ respectively, where the homozygous form represented $1.6 \%$ (FVL-G1691A) and $0 \%(\mathrm{PT}-\mathrm{G} 20210 \mathrm{~A})$ and the heterozygous form $2.1 \%$ (FVL -G1691A) and 0.5\% (PT-G20210A). These values are lower than studies carried out in other populations in Europe, Asia and North America (Caucasian populations), which have an incidence of FVL-G1691A in its heterozygous form of $22.8 \%$ and its homozygous form of up to $3 \%$, and of PT- G20210A up to $10 \%$ in 
its heterozygous form and $0.6 \%$ in its homozygous form..$^{46-57}$ Also, the presence of FVL-G1691A is associated with the development of venous thrombosis and deep vein thrombosis, as reported. As shown, ${ }^{58}$ in patients with deep vein thrombosis they have a higher rate of this mutation when compared with the control group (18 vs. 3.8\%); others identify. For their part, ${ }^{59,60}$ an incidence of $54 \%$ of FVL-G1691A in patients with deep vein thrombosis; a review, ${ }^{61}$ show an increase in the rate of FVL-G1691A in patients with venous thrombosis where values of $52 \%$ are shown compared to the control group that presented values of only $14.6 \%$, clearly expanding the knowledge of the role of FVL-G1691A in the development of venous thrombosis or deep vein thrombosis, another report. Attia F, et al., in 2009, observed the relationship between PT-G20210A and the development of deep vein thrombosis, in patients with deep vein thrombosis; a meta-analysis reports that patients with venous thrombosis have a higher incidence of PT-G20210A with values of up to $21.9 \%$ compared to the control group that presented values ${ }^{62}$ of up to $6.1 \%$. Regarding the presence of multiple thrombophilias per patient, ${ }^{63}$ reported an incidence of $13.3 \%$ of multiple thrombophilias per patient, without specifying the type of thrombophilias, which was not associated with the development of venous thrombosis. profound, it is different from our results that we had a low incidence of patients with combination of MTHFRC677T or PAI-1 4G/5G+FVL-G1691A or PT-G20210A ranging from 0.7 to $1.4 \%$, and a high incidence of the combination of MTHFRC677T+PAI-1 $4 \mathrm{G} / 5 \mathrm{G}$ which was $30.2 \%$. Of these results, 0.7 of the patients presented a combination of MTHFR-C677T and PTG20210A, a combination that was associated ${ }^{64}$ with the, in a 56-yearold patient, in which their parents, siblings and children presented this combination of thrombophilias, of which 4 out of 6 had pathologies related to the coagulation system.

Finally, as can be seen, there are a large number of studies that relate the presence of FVL-G1691A, PT-G20210A, MTHFR-C677T and PAI-1 4G/5G with the development of venous thrombi or deep vein thrombosis, it is important to highlight that the presence of any of these thrombophilias is not always indicative of the development of an alteration in hemostasis in favor of the development of venous thrombi or deep vein thrombosis, in many cases it is the mixture of factors that are part of the picture presented by patients who develop thrombotic events, such as oral contraceptives, the physiological changes of pregnancy and the puerperium with a state of hypercoagulation, hormone therapy for menopause, aging, sedentary lifestyle, obesity, surgery, serious infections, cancer, etc. ${ }^{44}$

\section{Study limitations}

The number of patients is low to represent the Mexican population, due they are only data obtained from a single health center. Even so, we believe that the study design shows a trend of the thrombophilias evaluated, which can be taken as a basis for future studies.

\section{Conclusion}

The population of Mexican women studied has a high rate of MTHFR-C677T and PAI-1 4G/5G, which makes them more susceptible to the development of thrombotic events. Furthermore, FVL-G1691A and PT-G20210A are of low incidence; but, it is combined with MTHFR-C677A Y/o PAI-1 4G/5G, increasing the effects of these thrombophilias; further studies on thrombophilias and the relationship with thrombotic events in Mexican women are required.

\section{Acknowledgments}

None.

\section{Funding}

None.

\section{Conflicts of interest}

The authors declare there are no conflicts of interest.

\section{References}

1. Latino $\mathrm{O}$, Bolati $\mathrm{H}$, Gerde $\mathrm{M}$, et al. Trombofilia en edad reproductiva. FASGO. 2015:1-17.

2. Pierre S, Noemie R, Manal I, et al. Common risk factors add to inherited thrombophilia to predict venous thromboembolism risk in families. $T H$ Open. 2019;3(1):e28-e35.

3. Ávila S, Gutiérrez J, Recurring abortion. Legal Medicine of Costa Rica; 2017.

4. Lilián D, Raúl M, Leonardo S, et al. Thrombophilia and pregnancy diagnostic and treatment guidelines. Arch Med Internal. 2011;XXXIII(Supl 2):S01-S20.

5. Gutiérrez-Castañeda MR, Font-López KC. Thrombophilias and pregnancy: incidence, risk factors, and perinatal outcomes. Ginecol Obstet Mex. 2017;85(10):676-684.

6. Ramírez K, Deep Venous Thrombosis. Revista Médica de Costa Rica y Centroamerica. 2014; LXXI(612):715-718.

7. Jaana N, Jaakko I, E-R Savolainen, et al. Placenta-mediated pregnancy complications are not associated with fetal or paternal factor $\mathrm{V}$ leiden mutation. Eur J Obstet Gynecol Reprod Biol. 2018;230:32-35.

8. Palomo I, Pereira J, Alarcón M, et al. Factor V leiden and prothrombin mutation G20210A in patients with venous and arterial thrombosis. Rev Méd Chile. 2005;133:1425-1433.

9. Stefanski AL, Christoph S, Rebecca FB, et al. Maternal thrombophilia and recurrent miscarriage - is there evidence that heparin is indicated as prophylaxis against recurrence? Geburtshilfe Frauenheilkd. 2018;78(3):274-282.

10. Parand A, Zolghadri J, Nezam M, et al, Inherited thrombophilia and recurrent pregnancy loss. Iran Red Crescent Med J. 2013;15(12):e13708.

11. Kumar A, Shrestha N, Joshi P, et al. Association of parental methylenetetrahydrofolate reductase (MTHFR) C677T gene polymorphism in couples whit unexplained recurrent pregnancy loss. BMC Reseach Notes. 2018;11(233):1-5.

12. Anil KS, Nisha S, Pratikshya J, et al. Association of parental methylenetetrahydrofolate reductase (MTHFR) C677T gene polymorphism in couples with unexplained recurrent pregnancy loss. BMC Res Notes. 2018;11(1):233.

13. Long S, Goldblatt J, MTHFR genetic testing: controversy and clinical implications. Aust Fam Physician. 2016;45(4):237-240.

14. Madurru D, Supriya K, Dirsipam K, et al. Relation between MTHFR (methylenetetrahydrofolate reductase) gene funtional polymorphysms and magnitude of recurrent pregnancy losses (RPL) among women with low socio-economic status in Asian Indians, Genet Mol Res. 2019;18(3):gmr16039962.

15. Philippe M, Rosalie C, Emmanuelle L, et al. Comparison of two preventive treatments for patients with recurrent miscarriages carrying a C677T methylenetetrahydrofolate reductase mutation: 5-year experience. $J$ Int Med Res. 2017;45(6):1720-1730 
16. Diala W Abu-Hassan, Abdullah N Alhouri, Nadera A Altork, et al. MTHFR gene polymorphisms in hypothyroidism and hyperthyroidism among jordanian females. Arch Endocrinol Metab. 2019;63(3):280 287.

17. Nair R, Khanna A, Singh K. MTHFR polymorphysm and recurrent pregnancy loss risck in north indian population. Reprod Sci. 2012;19(2):210-215

18. Luz E Goyco Ortiz, Edouard J Servy, Yves J R Menezo. A successful treatment with 5 methyltetrahydrofolate of a 677 TT MTHFR woman suffering premature ovarian insufficiency post a NHL (non-Hodgkin's Lymphoma) and RPL (Repeat Pregnancy Losses) J Assist Reprod Genet. 2019;36(1):65-67.

19. Parra I, López B, González I, et al. Coexistence of C677T and A1298C mutations in enzyme 5, 10 methylenetetrahydrofolate reductase. Mediagraphic. 2009;68(15):424-429.

20. Ana C, Valmore B, Elliuz L, et al. Plasminogen activator inhibitor type 1 (PAI-1) and its relationship with coronary atherosclerosis. Revista Latinoamericana de Hipertensión. 2007;2(5):151-156.

21. Isordia I Leaños A, Sainz A, Reyes E, et al. Association between 4G/5G polymorphism in the plasminogen-1 activator inhibitor (PAI-1) gene and ST-elevation acute myocardial infarction in young patients. Rev Esp Cardiol. 2009;62(4):365-372.

22. Madrigal Sanchez D, Frequency of the $4 \mathrm{~g} / 5 \mathrm{~g}$ polymorphism in the plasminogen-1 activator inhibitor (PAI-1) gene, in young patients with atherothrombotic brain disease, Master's Thesis, National Polytechnic Institute, Secretariat of Research and Graduate Studies, National School of Biological Sciences, Section for postgraduate studies and research. 2010.

23. González G, Sánchez C, Gómez M, et al. Self-concept in high risk pregnancy and recurrent gestational loss. Ginecol Obstet Méx. 2008;76(3):143-150.

24. Kiekebusch G, y Perucca E. Trombofilias hereditarias. Rev Chil Obstet Ginecol. 2003;68(15):424-429.

25. Li X, Liu Y, Zhang R, et al. Meta-analylis of the association between plasminogen activator inhibitor-1 $4 \mathrm{G} / 5 \mathrm{G}$ polymorphism and recurrent pregnacy loss. Med Sci Monit. 2015;21:1051-1056.

26. Mateo S, Mateo H, Hernández L, et al. Recurrent loss of pregnancy: bibliographic review. Ginecol Obstet Méx. 2016;84(8):523-534.

27. Said JM, Tsui R, Borg AJ, et al. The PAI-1 4G/5G polymorphismis not associated with an increased risk of adverse pregnancy outcome in asymptomatic nulliparous women. J Thromb Haemost. 2012;10:881886.

28. Gutiérrez M, Font K. Thrombophilias and pregnancy: incidence, risk factors and perinatal outcomes. Ginecol Obstet Méx. 2017;85(10):676684.

29. Donevic V, Gvozdenov M, Pruner I, et al. The prevalence of PAI-1 $4 \mathrm{G} / 5 \mathrm{G}$ polymorphism in women with fetal loss - first data for a sercvian population. J Med Biochem. 2014;33(2):203-207.

30. Joaquín V Gonzalez, Andrés G Barboza, Fernando J Vazquez, et al Prevalence and geographical variation of prothrombin G20210A mutation in patients with cerebral vein thrombosis: a systematic review and meta-analysis. PLoS One. 2016;11(3):e0151607.

31. Fatemeh S, Mohammad TA, Shohreh ZK, et al. Association of plasminogen activator inhibitor-1 and angiotensin converting enzyme polymorphisms with recurrent pregnancy loss in Iranian women. Iran J Reprod Med. 2015;13(10):627-632.
32. Wilcken B, Bamforth F, Li Z, et al. Geographical and ethnic variation of the $677 \mathrm{C}>\mathrm{T}$ alelle of 5,10 methylenetetrahydrofolate reductase (MTHFR): finding from over 7000 newborn from 16 areas worldwide. Journal of Medical Genetics. 2003;40:619-625.

33. Wilcken B, Bamforth F, Li Z, et al. Geographical and ethnic variation of the $677 \mathrm{C}>\mathrm{T}$ alelle of 5,10 methylenetetrahydrofolate reductase (MTHFR): finding from over 7000 newborn from 16 areas worldwide. Journal of Medical Genetics. 2003;40:619-625.

34. Iglal YS, Akram AMD, Reham AH, et al. Department of clinical pathology, alexandria university, Egypt detection of plasminogen activator inhibitor-1 (-675 4G/5G) gene polymorphism in women with recurrent abortion. Hematol Transfus Int J. 2019;7(4):41-44.

35. Yuan Z, Xia H, Xuan X, et al. The association between maternal methylenetetrahydrofolate reductase C677T and A1298C. Prenat Diagn. 2019;39(1):3-9.

36. Brezovska J, Krstevska M, Baliskova G, et al. Hyperhomocysteinemia and of methylenetetrahydrofolate reductase (C677T) genetic polymorphism in patients with deep vein thrombosis. Mater Socio Med. 2013;25(3):170-174.

37. Ghaznavi H, Soheili Z, Samiei S, et al. Association of methylenetetrahydrofolate reductase $\mathrm{C} 677 \mathrm{~T}$ polymorphism with hyperhomocysteinemia and deep vein thrombosis in the iranian population. Vasc Specialist Int. 2015;31(4):109-114.

38. Munshi R, Panchal F, Kulkarni V, et al. Methylenetetrahydrofolate reductase polymorphism in healthy volunteers and its correlation with homocysteine levels in patients with thrombosis. Indian J Pharmacol. 2019;51:248-254

39. Aniket P, Shrimati S, Kanjaksha G, et al. Investigation of plasminogen activator inhibitor-1 (PAI-1) 4G/5G promoter polymorphism in indian venous thrombosis patients: a case-control study. Eur J Haematol. 2017;99(3):249-254.

40. Ehsani M, Imani A, Moravveji A, Prevalence of factor V leiden, MTHFR C677T and MTHFR A1298C polymorphisms in patients with deep vein thrombosis in central Iran. Molecular Biology Reports. 2018;45(4);621-624.

41. Ehsani M, Imani A, Moravveji A, Prevalence of factor V leiden, MTHFR C677T and MTHFR A1298C polymorphisms in patients with deep vein thrombosis in central Iran. Molecular Biology Reports. 2018;45(4);621-624.

42. Ghaffari K, Ghasemi A, Ghotaslou, et al. Correlation between C677T and A1298C mutation on the MTHFR gene with plasma homocyteine level and venous thrombosis in pregnant women at risk of thrombosis. Zahedan Journal of Research in Medical Sciences. 2015;17(12):e5192.

43. Habib G, Zahra S, Shahram S, et al. Association of methylenetetrahydrofolate reductase $\mathrm{C} 677 \mathrm{~T}$ polymorphism with hyperhomocysteinemia and deep vein thrombosis in the Iranian population. Vasc Specialist Int. 2015;31(4):109-114.

44. Cristiane AM, Julia B Rocha, Daiane C Costa, et al. Prevanelce of facor $\mathrm{V}$ leiden in patients whit venous thrombosis. J Bras Patol Med Lab. 2016;52(4):227-232.

45. Prabhudesai A, Shetty S, Ghosh K, et al. Investigation of plasminogen activator inhibitor-1 (PAI-1) 4G/5G promoter polymorphism in Indian venous thrombosis patients: A case-control study. Eur J Haematol. 2017;99(3):249-254.

46. Ahmed N, Adam I, Eldin S, et al. Factor-V leiden G1691A and prothrombin G20210A polymorphisms in sudanese women with preeclampsia, a case-control study. BMD Medical Genetics. 2019;20(2):1-5. 
47. Nadir A Ahmed, Ishag Adam, Salah Eldin G Elzaki, et al. Factor-V leiden G1691A and prothrombin G20210A polymorphisms in sudanese women with preeclampsia, a case -control study. BMC Med Genet. 2019;20:2

48. Alfirevic Z, Simundic A, Nicolak N, et al., Frecuency of Factor II G20210A, Factor V leiden, MTHFR C677T and PAI-1 5G/4G polymorphism in patients with venous thromboembolism: croatian case-control study. Biochemia Medica. 2010;20(2):229-235

49. Ahmed A, Meriem M, Aicha S, et al. Association of FV G1691A polymorphism but not A4070G with coronary artery disease. Clin Appl Thromb Hemost. 2018;24(2):330-337.

50. Nourelhouda C, Abbassia D, S Cheriftouil. Frequency of factor II G20210A and factor V leiden mutations in algerian patients with venous thromboembolism. Journal of Blood Disorders and Transfusion. $2015 ; 6: 1-4$.

51. Margaret D, Laxmi VB. Global prevalence of prothrombin gene mutation G20210A and implications in women's health: a systematic review. Blood Coagul Fibrinolysis. 2016;27(5):481-489.

52. Husham OE, Alaa AS, Alaa AY, et al. Evaluation of factor V leiden and prothrombin G20210A mutations in sudanese women with severe preeclampsia. Curr Res Transl Med. 2020;68(2):77-80.

53. Brizeida AS, Yahveth CF, Juan Carlos OG, et al. Primary thrombophilia in Mexico XIII: localization of the thrombotic events in Mexican mestizos with the sticky platelet syndrome. Clin Appl Thromb Hemost. 2019.

54. Schneider JG, Eynatten MV, Dugi KA, et al. Recurrent deep venous thrombosis caused by congenital interruption of the inferior vena cava and heterozygous factor $\mathrm{V}$ leiden mutation. $J$ Intern Med. 2002;252:276-280

55. Mohammad TK, Elham Y, Azra A, et al. Association of factor V leiden and prothrombin G20210A polymorphisms in Women with recurrent pregnancy loss in Isfahan province, Iran. Int J Prev Med. 2018;9:13.
56. Montaño M, Frías S, Rojo S, et al. Tromboembolismo pulmonar bilateral masivo puerperal, secundario a trombosis venosa profunda intraparto. A propósito de un caso. Ginecol Obstet Méx. 2017;85(10):711-717.

57. Iván Palomo G, Jaime Pereira G, Marcelo Alarcón L, et al. Factor V leiden y mutación de la protrombina G20210A en pacientes con trombosis venosa y arterial. Rev Méd Chile. 2005;133:1425-1433.

58. A Jusić-Karić, R Terzić, Z Jerkić, et al. Frequency and association of $1691(\mathrm{G}>\mathrm{A})$ FVL, $20210(\mathrm{G}>\mathrm{A})$ PT and 677 (C>T) MTHFR with deep vein thrombosis in the population of Bosnia and Herzegovina. Balkan Journal of Medical Genetics. 2016:19(1).

59. Mehrez M Jadaon. Epidemiology of prothrombin G20210A mutation in the mediterranean region. Mediterr $J$ Hematol Infect Dis 2011;3(1):e2011054.

60. Federici EH, Al-Mondhiry H. High risk of thrombosis recurrence in patients with homozygous and compound heterozygous factor $\mathrm{V}$ R506Q (Factor V Leiden) and prothrombin G20210A. Thrombosis Research. 2019;182:75-78.

61. Syed Shafiaa, Mahrukh HZ, Nabeela K, et al. High prevalence of factor V Leiden and prothrombin G20101A mutations in Kashmiri patients with venous thromboembolism. Gene. 2018;654:1-9.

62. Gonzalez JV, Barboza AG, Vazquez FJ, et al. Prevalence and geographical variation of prothrombin G20210A mutation in patients with cerebral vein thrombosis: a systematic review and meta-analysis. PLoS ONE. 2016;11(3):e0151607.

63. Kearon C, Akl EA, Ornelas J, et al. Antithrombotic therapy for VTE disease: CHEST guideline and expert panel report. Chest. 2016;149(2):315-352

64. Silvia IÁ, Eva BO, Francisco MLS, et al. A deep vein thrombosis caused by $20209 \mathrm{C}>\mathrm{T}$ mutation in homozygosis of the prothrombin gene in a Caucasian patient. Biochemia Medica. 2014;24(1):159-166. 